\title{
A New Zero-Voltage-Switching Push-Pull Converter
}

\author{
Yisheng Yuan, Qunfang Wu \\ School of Electrical and Electronics Engineering, East China Jiaotong University, Nanchang, China \\ Email: cloudstone_yuan@yahoo.com.cn, qfwu55@yahoo.com.cn
}

Received March, 2013

\begin{abstract}
A soft switching three-transistor push-pull (TTPP) converter is proposed in this paper. The 3rd transistor is inserted in the primary side of a traditional push-pull converter. Two primitive transistors can achieve zero-voltage-switching (ZVS) easily under a wide load range, the 3rd transistor can also realize zero-voltage-switching assisted by leakage inductance. The rated voltage of the $3 \mathrm{rd}$ transistor is half of that of the main transistors. The operation theory is explained in detail. The soft-switching realization conditions are derived. An $800 \mathrm{~W}$ with $83.3 \mathrm{kHz}$ switching frequency prototype has been built. The experimental result is provided to verify the analysis.
\end{abstract}

Keywords: Push Pull Converter; Extra Transistor; Zero-voltage-switching

\section{Introduction}

The soft-switching technology can reduce device stress, switching loss, electromagnetic interference (EMI) and improve power density of the power electronic equipment. Over the last two decades, the most researches focus on the improved ZVS and ZVZCS phase-shifted full-bridge circuit [1-6] and their applications. But comparatively, the research on soft switching push-pull converter is very seldom. Taking LLC resonant technique for example, in recent years, LLC resonant converter based on half-bridge circuit, three- level circuit, full-bridge circuit and interleaved combined circuit [7-12] attracted lots of interest, owing to its full soft-switching realization for all power transistors and rectifier diodes. But in LLC resonant converters' family, the push-pull converter is exceptive. A push-pull converter has two transformer primary windings, which is impossible to have a LLC link inserted in the primary side. Converter in [13] shows soft switching behavior of the push-pull circuit with a LC resonant link in secondary side. But further research in [14] shows that there exists N-period resonant status in this type of the push-pull converter and its output will work as either constant voltage source or constant current source. Similarly, LCL resonant push-pull converter [15-17] where resonant components are located in either primary side or secondary side can also realize ZVS of power switches, but can not adjust its output voltage. Furthermore, the LCL resonant push-pull converter [18] with an additional parallel resonant inductor $L_{s r}$ can realize ZVS for power switches and can adjust its output voltage by frequency modulation. But in order to improve boost ratio, the additional parallel resonant induc- tor $L_{s r}$ has to be designed so small that extra power loss is become larger. Besides the above passive soft-switching push-pull converter, Active-clamped push-pull circuit in [19] can achieve ZVS for its main power switches, but its drawbacks are that the maximum duty cycle of main power switches is limited by active-clamped circuit. The three-level push-pull circuit [20] controlled by phaseshifted PWM mode can obtain ZVS condition for power switches, but its controller UC3875 is expensive. Both these two active soft-switching push-pull converters require four power switches and their driving logics is complex.

This paper proposes a three-transistor push-pull (TTPP) converter. ZVS can be achieved for all three transistors based on the proposed driving logic. The TTPP converter can be controller by a general PWM IC of SG3525.

\section{Operation Principle}

\subsection{Converter Topology}

The proposed TTPP converter is showed in Figure 1. An extra transistor $Q_{3}$ is inserted between the power source $U_{\text {in }}$ and midpoint of two primary windings. Diodes $D_{1}$, $D_{2}$ and $D_{3}$ are body diodes of the transistors $Q_{1}, Q_{2}$ and $Q_{3}$ respectively. Capacitors $C_{1}, C_{2}$ and $C_{3}$ include the parasitic capacitor of power transistors and external parallel capacitors. The inductance $L_{\text {leak }-1}$ and $L_{\text {leak-2 }}$ represent the leakage inductances of the primary winding $P_{1}$ and $P_{2}$ respectively.

\subsection{PWM Mode}

The PWM signals of the three power transistors are 
showed in Figure 2. The duty cycle of the $Q_{1}$ and $Q_{2}$ are higher than 0.5 , and they are $180^{\circ}$ out of phase. The switching frequency of $Q_{3}$ is twice of that of $Q_{1}$ and $Q_{2}$.

1 and 0 represent switch on and switch off respectively. Neglecting the dead time, such as $t_{1} \sim t_{2}, t_{3} \sim t_{4}$, the operating status of the $Q_{1}, Q_{2}$ and $Q_{3}$ can be divided into four states, $101 \rightarrow 110 \rightarrow 011 \rightarrow 110$ in a complete cycle. To ensure voltage-second balance of the transformer in a switching cycle, the state 101 is lasts as long as the state 011.

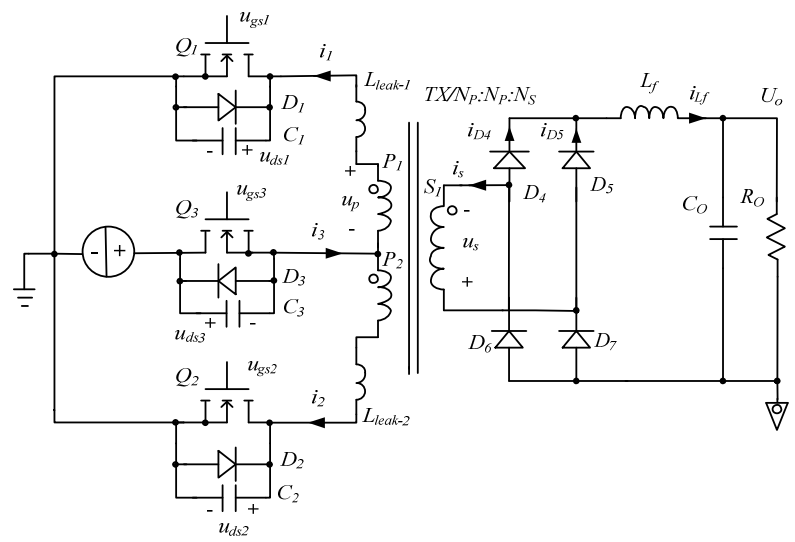

Figure 1. The proposed converter.

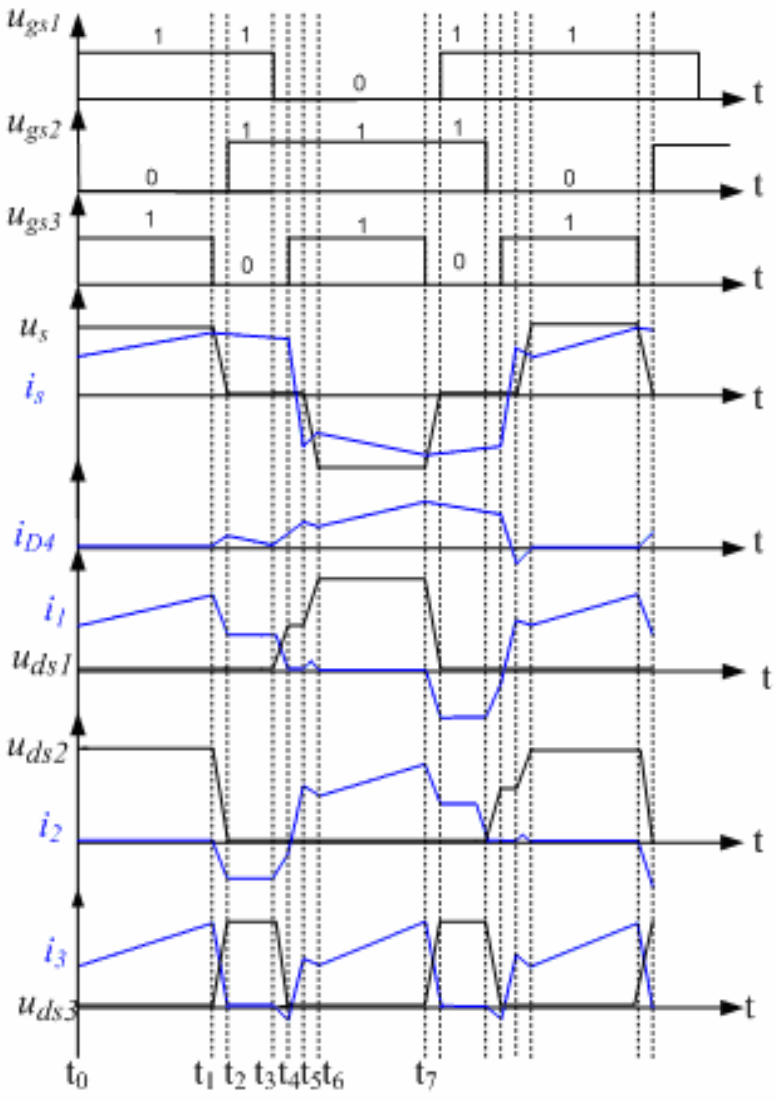

Figure 2. Main operation waveforms.
The state 101 and 011 are normal energy deliver stages from the primary side to the secondary side. Conversely, during state 110 , the transistor $Q_{1} \& Q_{2}$ are both conducted and the energy is circulating in the primary side loop.

\subsection{Operation Principle}

To simplify the analysis of operation stage, the following conditions are assumed.

1) The voltage drop of the power MOSFETS and DIODES during on state is zero.

2) $C_{1}=C_{2}=C_{3}=C_{\text {leak }}$.

3) $L_{\text {leak }-1}=L_{\text {leak }-2}=L_{\text {leak }}$.

4) The output filter inductance can be modeled as a constant current source during the dead time.

The operation process of the TTPP converter in half of cycle can be divided into six stages. The main operation waveforms are shown in Figure 2. Figure 3 shows the equivalent circuit at different modes.

1) Mode $1\left[t_{1}-t_{2}\right]$.

Before $t_{1}$, transistor $Q_{1}$ and $Q_{3}$ are both conducting, the energy transfer from $U_{\text {in }}$ to the transformer secondary winding and the current of the filter inductance $L_{\mathrm{f}}$ increases. At $t_{1}, Q_{3}$ is turned off. If the capacitor $C_{3}$ is large

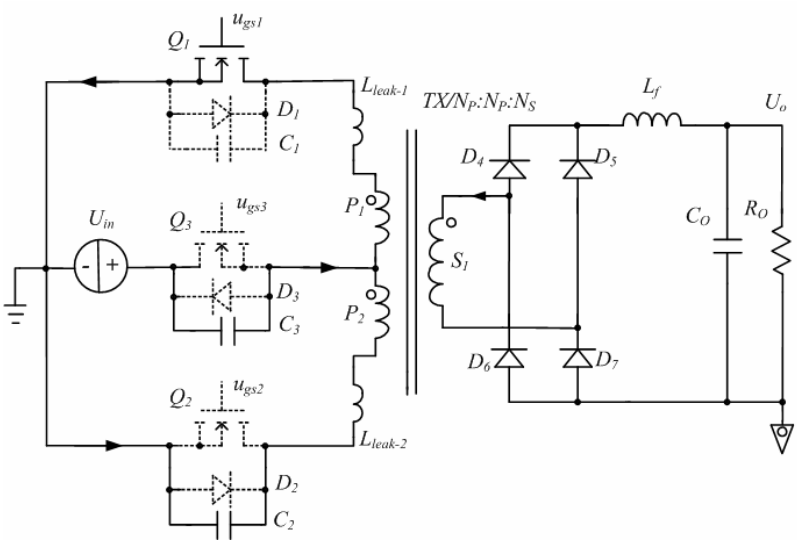

(a) $\left[t_{1}-t_{2}\right]$

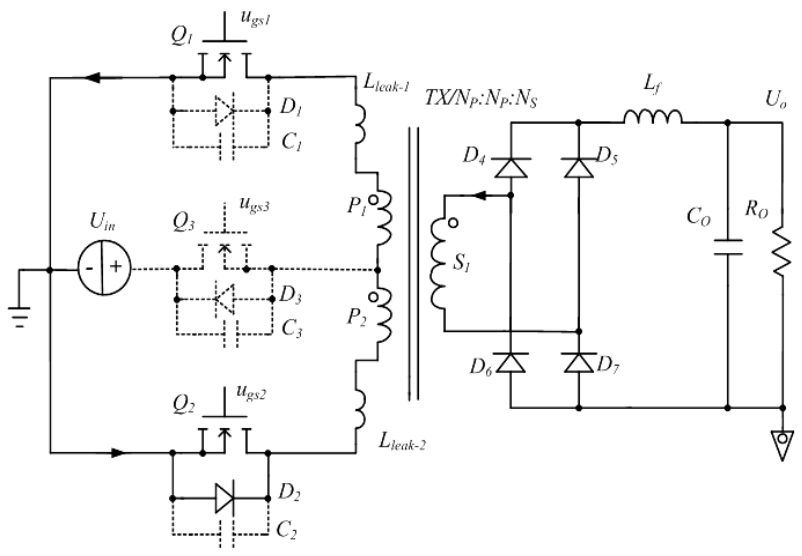

(b) $\left[t_{2}-t_{3}\right]$ 


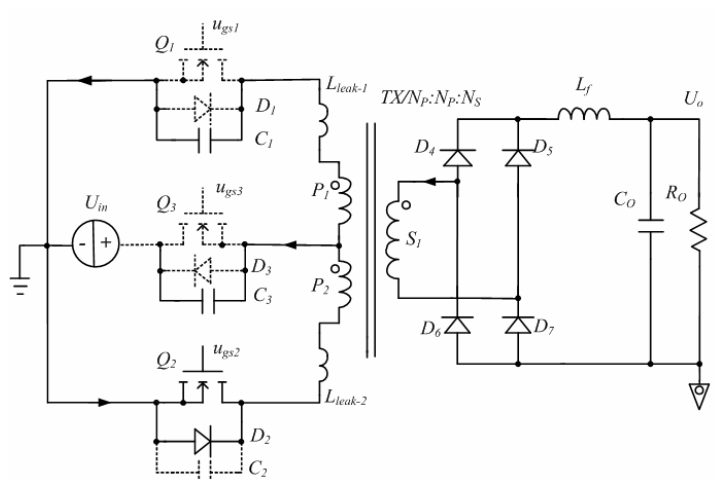

(c) $\left[t_{3}-t_{4}\right]$

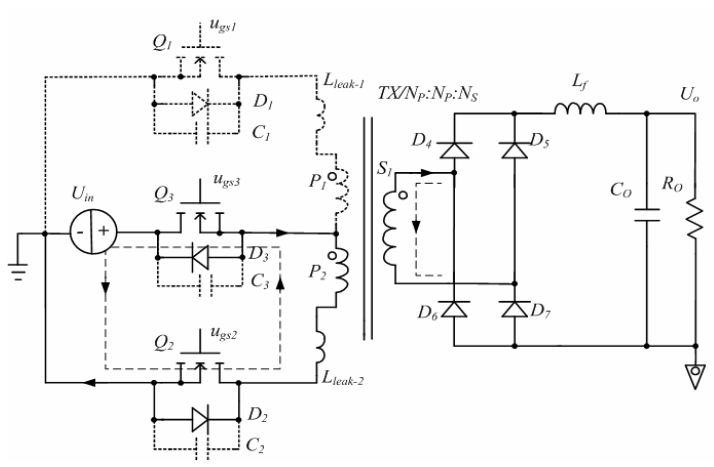

(d) $\left[t_{4}-t_{5}\right]$

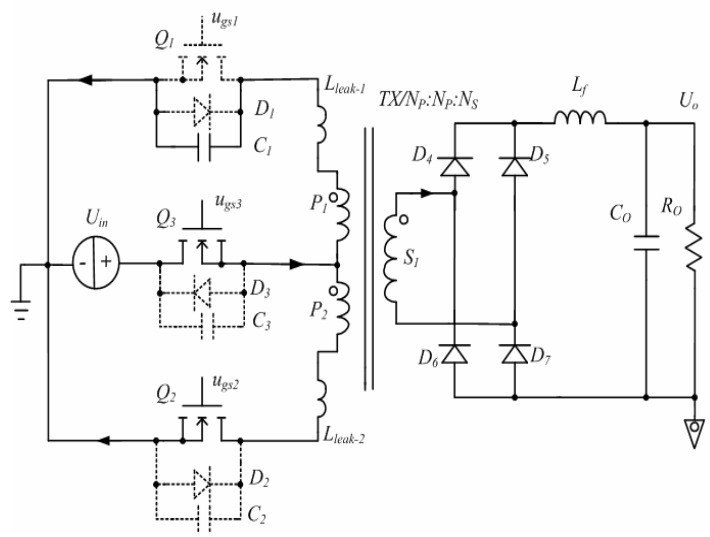

(e) $\left[t_{5}-t_{6}\right]$

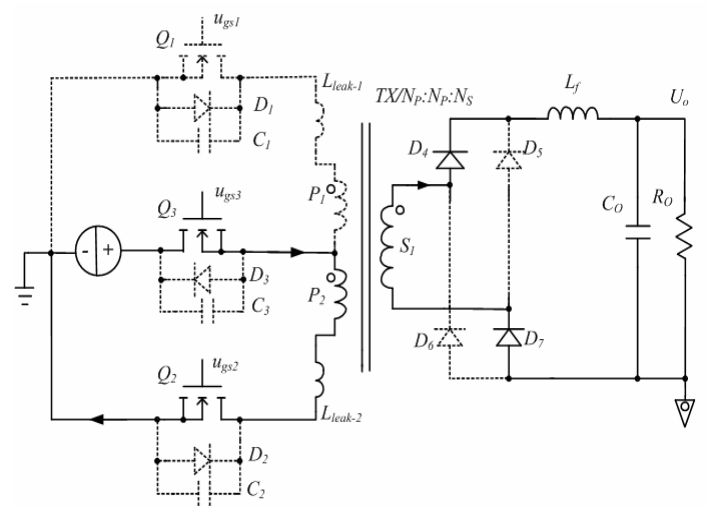

(f) $\left[t_{6}-t_{7}\right]$

Figure 3. Equivalent circuit at different modes. enough, the rising time of $u_{d s 3}$ is more than several time of falling time of $i_{d s 3}, Q_{3}$ can achieve zero-voltage turn-off. In this mode, the inductance $L_{f}$ will keep freewheeling and be reflected to the primary side to resonant with capacitance $C_{3}$ and $C_{2}$. Because current through $L_{f}$ is high enough, the voltage $u_{d s 3}$ will rise from zero up to $U_{\text {in }}$ with $u_{d s 2}$ falling from $2 U_{\text {in }}$ to zero. At the same time, the transformer primary side voltage $u_{P}$ reduces to zero.

Assuming that the initial current of primary side loop in this mode is equal to $I_{p}$, the loop voltage equation and junction current equation in primary side can be established as

$$
\left\{\begin{array}{l}
U_{\text {in }}-u_{d s 3}-u_{p}-L_{\text {leak }} \frac{d i_{1}}{d t}=0 \\
U_{\text {in }}-u_{d s 3}+u_{p}-u_{d s 2}-L_{\text {leak }} \frac{d i_{2}}{d t}=0 \\
I_{p}=i_{1}-i_{2} \\
i_{3}=i_{1}+i_{2} \\
i_{2}=C \cdot d u_{d s 2} / d t \\
i_{3}=C \cdot d u_{d s 3} / d t
\end{array}\right.
$$

Right before $t_{2}$, transformer voltage $\mathrm{u}_{\mathrm{p}}$ falls to zero. Combining this end condition with equation (1), the end status of this mode can be derived with approximation as in Equation (2),

$$
\left\{\begin{array}{l}
u_{d s 2}=0 \\
u_{d s 3}=U_{i n} \\
i_{1}=I_{P} / 2 \\
i_{2}=-I_{P} / 2 \\
t_{2}-t_{1}=5 C U_{i n} / I_{P}
\end{array}\right.
$$

Meanwhile, in the secondary side, in general opinion, $D_{5} \& D_{6}$ keep conducting and $D_{4} \& D_{7}$ keep turn off. But in practical, because the transformer voltage fall down to zero quickly, the parasitic capacitor of the secondary side of the transformer will produce a discharge current $i_{\text {dis }}$ which will cancel part of the current of the secondary side and reduce the current through $D_{5} \& D_{6}$. So $D_{4} \& D_{7}$ also conduct in order to keep the current of $\mathrm{L}_{\mathrm{f}}$ constant. In this micro-commutation mode, the current of $D_{4} \& D_{7}$ is so small that it neglected in most papers. In this paper, it is defined as micro-commutation mode.

2) Mode $2\left[t_{2}-t_{3}\right]$.

At $t_{2}$ moment, the diode $D_{2}$ begins to conduct because $u_{d s 2}$ fall down to zero. This means that transistor $Q_{2}$ can achieve zero-voltage turn-on.

In this mode, $D_{2}$ and $Q_{1}$ are on and current circulates in the primary side. Neglecting the voltage-drop of $\mathrm{D}_{2}$ and $Q_{1}$, the circulating current in the primary side maintain at $I_{p} / 2$.

In the secondary side, $L_{f}$ sustains negative voltage $-U_{o}$ 
and $i_{L f}$ begin dropping. This will drive the currents of $D_{4} \sim D_{7}$ reducing. It can be derived as:

$$
\left\{\begin{array}{l}
i_{S}=\frac{N_{P}}{N_{S}} \cdot I_{P} \\
i_{D 4}+i_{D 7}=i_{L f} \\
i_{S}+i_{D 7}=i_{D 4} \\
i_{L f}=i_{L f}\left(t_{2}\right)-\frac{U_{O} \cdot d t}{L_{f}}
\end{array}\right.
$$

As a result, $i_{D 4}$ may fall down to zero.

3) Mode $3\left[\mathrm{t}_{3}-\mathrm{t}_{4}\right]$

At $t_{3}, Q_{1}$ is turned off. $Q_{1}$ can achieve zero voltage turn off due to $C_{1}$. The current $i_{1}$ flows through $Q_{1}$ decreasing rapidly, causing the secondary rectifier begin commutating. The current $i_{D 5} \& i_{D 6}$ decreases quickly and synchronously, $i_{D 4} \& i_{D 7}$ increase quickly. In the primary side, the leakage inductances of $L_{\text {leak }-1} \& L_{\text {leak }-2}$ resonate with the capacitances of $C_{1} \& C_{3}$. The voltage $u_{d s 1}$ increases while $u_{d s 3}$ falls down at the same time. The secondary current reflects the change of primary resonance current.

In this mode, the following equations can be derived,

$$
\left\{\begin{array}{l}
i_{3}=i_{1}+i_{2} \\
i_{1}=C \frac{d u_{d s 1}}{d t} \\
i_{3}=C \frac{d u_{d s 3}}{d t} \\
U_{\text {in }}-u_{d s 3}=L_{\text {leak }} \frac{d i_{1}}{d t}+u_{d s 1} \\
U_{\text {in }}-u_{d s 3}=L_{\text {leak }} \frac{d i_{2}}{d t}
\end{array}\right.
$$

when the energy of leakage inductance is large enough, $u_{d s 1}$ increases from zero to $U_{i n}, u_{d s 3}$ decreases from $U_{i n}$ to zero, $i_{1}$ drops to zero, $i_{2}$ drops to equal $i_{3}$, and $D_{3}$ starts to conduct. As a result, it provides the $Q_{3}$ ZVS condition.

The time required for voltage $u_{d s 3}$ dropping to zero or voltage $u_{d s 1}$ to rise from zero to $U_{i n}$ can be simplified as

$$
t_{34}=\frac{2 C U_{\text {in }}}{i_{1}\left(t_{3}\right) / 2}
$$

4) mode $4\left[\mathrm{t}_{4}-\mathrm{t}_{5}\right]$

At $t_{4}$, the voltage $u_{d s 3}$ is zero, $Q_{3}$ is turned on and zerovoltage turn-on is achieved. In this interval, the voltage $U_{\text {in }}$ applies on the leakage inductance $L_{\text {leak-2 }}$. The current $i_{2}$ and $i_{3}$ can be expressed as,

$$
i_{2}=i_{3}=i\left(t_{4}\right)+\frac{U_{\text {in }} \cdot d t}{L_{\text {leak }}}
$$

with the change of $i_{2}$ and $i_{3}$, the secondary rectifier continues commutating. The current $i_{D 5} \& i_{D 6}$ decreases quickly and synchronously, $i_{D 4} \& i_{D 7}$ increase quickly. At the end of this stage, the currents $i_{D 5} \& i_{D 6}$ reach their peak reverse recovery current, accordingly the current $i_{2} \& i_{3}$ change from negative across zero, until its value reflected to the secondary side reach the sum of $i_{D 4}$ and peak reverse recovery current $i_{D 5}$.

5) Mode $5\left[\mathrm{t}_{5}-\mathrm{t}_{6}\right]$

At $t_{4}$, diode $\mathrm{D}_{5} \& \mathrm{D}_{6}$ begin sustain reverse voltage quickly, leading the voltage of secondary winding begins be reverse quickly. As a result, the voltage of primary windings $P_{1}$ is also reversed with the secondary voltage. The magnetizing inductance $L_{m}$ resonants with $C_{1}$. Voltage $u_{d s 1}$ rises from $U_{i n}$ to $2 U_{i n}, u_{p}$ rises from zero to $U_{i n}$.

In this mode, with the decreasing of reverse recovery current of $D_{5} \& D_{6}$, the current $i_{s}, i_{2}$ and $i_{3}$ also decrease synchronously. This mode finishes when $i_{D 5} \& i_{D 6}$ recovery to zero and $u_{p}$ arrives $U_{i n}$.

6) Mode 6[t $\left.\mathrm{t}_{6}-\mathrm{t}_{7}\right]$

In this mode, the converter run in a normal operation status and energy is transferred from input to output. The current of $L_{f}$ increases linearly and the value can be expressed as follows,

$$
i_{L f}=i_{L f}\left(t_{5}\right)+\frac{\left(U_{i n} \cdot N_{s} / N_{p}-U_{o}\right) \cdot d t}{L_{f}}
$$

At $t_{7}, Q_{3}$ is turned off; the converter begins the next half of cycle.

\section{Design Guidelines}

\subsection{Duty Cycle Loss}

According to the above analysis, the duty cycle $\alpha_{3}$ of extra transistor $Q_{3}$ determines the ratio between $U_{o}$ and $U_{\text {in }}$. But during $t_{5}$ to $t_{6}$, there is a duty cycle loss $\alpha_{\text {loss. }}$. It is derived approximately as,

$$
\alpha_{\text {loss }}=\frac{t_{56}}{T_{s}}=\frac{i_{3}\left(t_{6}\right)}{L_{\text {leak }} T_{s}}
$$

where $T_{s}$ represents the switching period of $Q_{3}$. Then

$$
\frac{U_{O}}{U_{\text {in }}}=\left(\alpha_{3}-\alpha_{\text {loss }}\right) \cdot \frac{N_{S}}{N_{P}}
$$

\subsection{Voltage Stress of Power Switches}

The voltage stress of main transistors $Q_{1} \& Q_{2}$ is $2 U_{i n}$, while that of the extra transistor $Q_{3}$ is $U_{i n}$.

\subsection{Soft-switching Condition}

A) Main transistors $Q_{1} \& Q_{2}$

The ZVS condition of $Q_{1}$ and $Q_{2}$ is determined by $L_{f}$ energy. In mode $1, u_{d s 3}$ should rise from zero to $U_{i n}$ and $u_{d s 2}$ should fall from $2 U_{i n}$ to zero. So the condition of main transistor realizing soft-switching can be derived as

$$
L_{f} I_{L f}^{2}>5 C U_{i n}^{2}
$$


According to (14), the minimum load for obtain ZVS of $Q_{1}$ and $Q_{2}$ can be derived, as well as the minimum dead time $t_{1} \sim t_{2}$.

In addition, the turn-off loss of main transistor $Q_{1} \& Q_{2}$ are far less than that in the traditional push-pull converter. In the traditional push-pull converter, the power switches are turned off at the peak current with a big turn-off losses. However, $Q_{1} \& Q_{2}$ in this TTPP converter are turned off at half of peak current as that of traditional push-pull converter. Furthermore, the parallel capacitor of $Q_{1} \& Q_{2}$ can reduce turn-off losses greatly.

B) Extra transistor $Q_{3}$

The ZVS condition of the extra transistor $Q_{3}$ is determined by the energy of leakage inductance. It can be expressed as,

$$
L_{\text {Leak }} i^{2}\left(t_{3}\right)>2 C U_{\text {in }}^{2}
$$

Obviously, the ZVS of $Q_{3}$ couldn't be obtained easily under a light load or with small leakage inductance. In fact, adding a series inductance will be a recommended method to improve ZVS condition of $Q_{3}$.

\section{Experimental Results}

The performance of the TTPP converter has been verified with a prototype circuit operating at $83.3 \mathrm{kHz}, 140$ $\mathrm{V} \sim 150 \mathrm{~V}$ input voltage, $180 \mathrm{~V}$ output voltage and $800 \mathrm{~W}$ power. The transformer is implemented with an EE42 core and windings with turn ratio of 24:24:42. Power MOSFETs of SPW20N60C3 and diodes of RHRP1560 are used in the prototype.

The tested gate signals of three power transistors and the secondary voltage of the transformer are shown in Figure 4. The logics relation of three driving signals is same as Figure 2. The secondary voltage is a three-level waveform.

Figure 5 shows the measured waveforms of the proposed converter at full load. It is obvious that $Q_{1}$ achieves zero-voltage turn-on and turn off at half of peak current as shown in Figure 5(a). The extra $Q_{3}$ also obtain zero-voltage turn-on as showed in Figure 5(b). Figure 5(c) shows that the secondary current has a quick drop

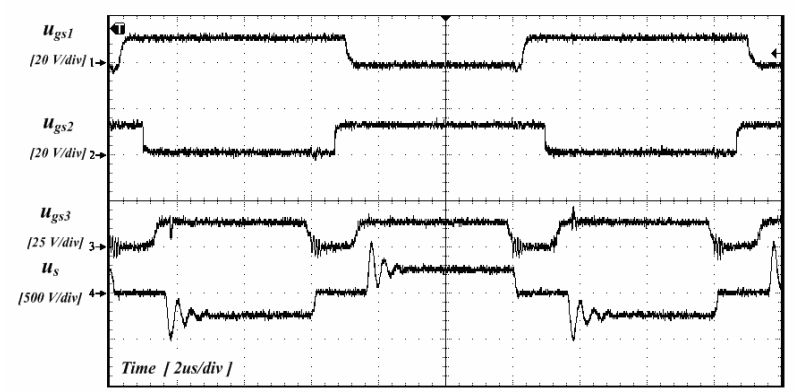

Figure 4. Three driver signals and secondary voltage waveforms.

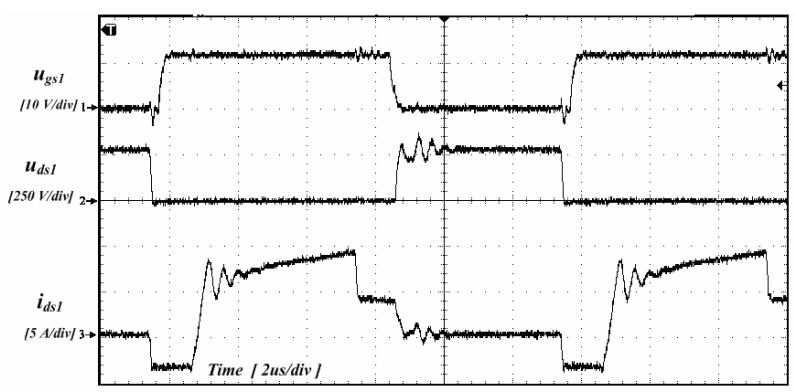

(a) $\mathrm{u}_{\mathrm{gs} 1}, \mathrm{u}_{\mathrm{ds} 1}, \mathrm{i}_{\mathrm{ds} 1}$

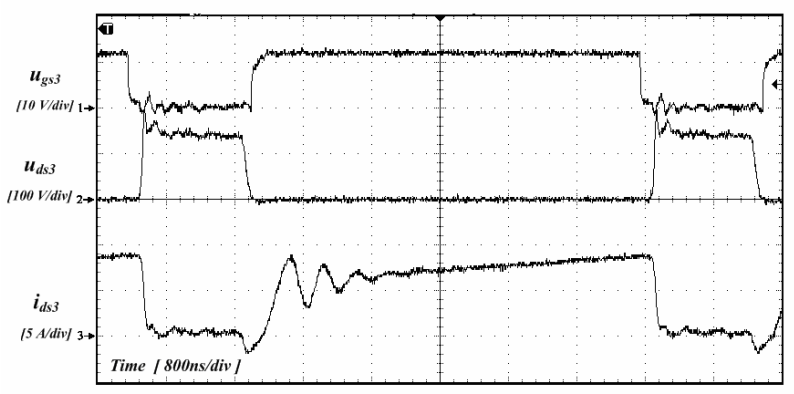

(b) $\mathrm{u}_{\mathrm{gs} 3}, \mathrm{u}_{\mathrm{ds} 3}, \mathrm{i}_{\mathrm{s}}$



(c) $u_{\mathrm{s}}$ and $i_{\mathrm{s}}$

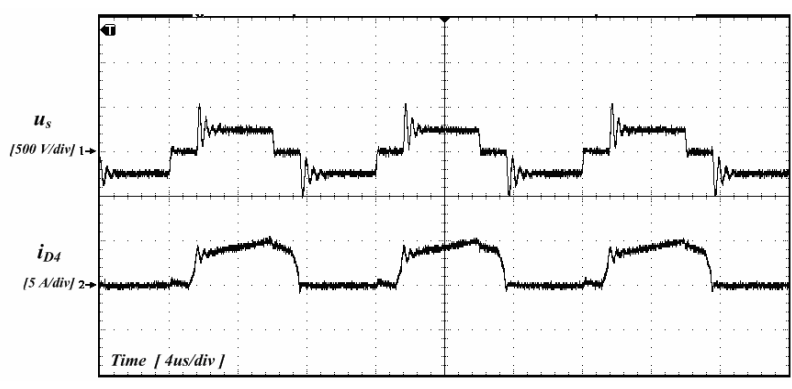

(d) $u_{\mathrm{s}}$ and $\mathrm{i}_{\mathrm{D} 4}$

Figure 5. Experimental waveforms with full load.

when $Q_{3}$ turns off. This phenomenon is produced by discharger current of parasitic capacitor of transformer as described in mode 1. The micro-commutation process of four diodes as $Q_{3}$ turn-off is also showed as $i_{D 4}$ in Figure 5(d). In addition, the duty cycle loss can be found in Figure 5(c).

The main transistor $Q_{1}$ also achieves ZVS under 250 $\mathrm{W}$ load as shown in Figure 6. $Q_{3}$ can no longer achieve zero-voltage turn-on at $450 \mathrm{w}$ load as shown in Figure 7, 


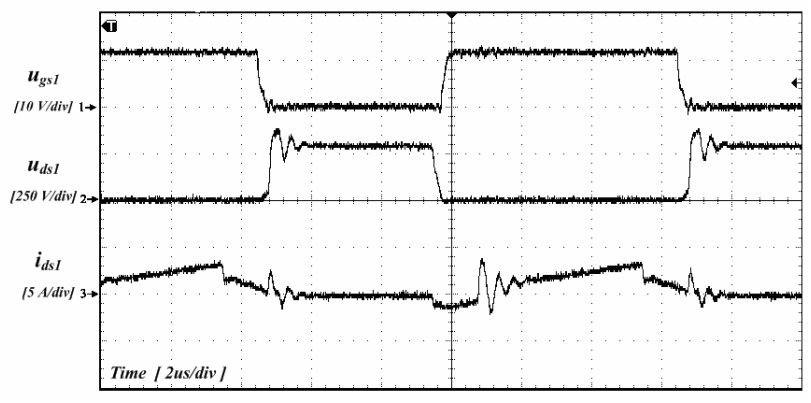

Figure 6. $u_{\mathrm{gs} 1}, \mathrm{u}_{\mathrm{ds} 1}$ and $i_{\mathrm{ds} 1}$ waveforms with $250 \mathrm{~W}$ load.

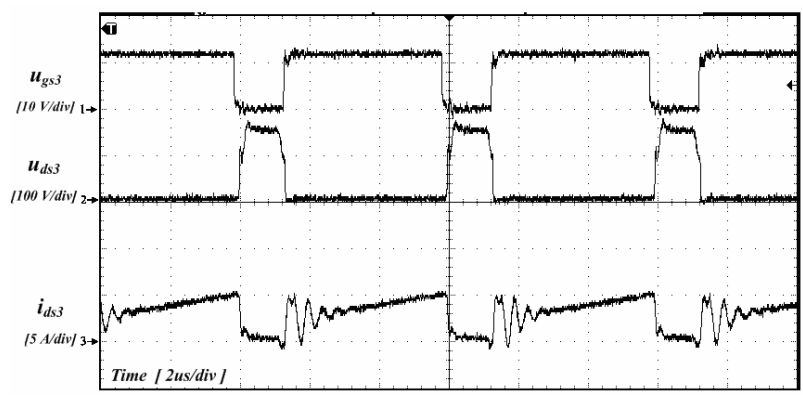

Figure 7. $u_{\mathrm{gs} 3}, u_{\mathrm{ds} 3}$ and $i_{\mathrm{ds} 3}$ waveforms with $450 \mathrm{~W}$ load.

but only hard switching on as $u_{d s 3}$ drops to $100 \mathrm{~V}$.

The measured efficiency of this TTPP converter at full load is $94.8 \%$.

\section{Conclusions}

A TTPP converter which can achieve ZVS is presented in this paper. It only requires an extra transistor to be inserted between the input power source and midpoint of two primary windings in traditional push-pull converter. Adopting phase-shifting concept, the logic of the three driving signals is similar to that in phase-shift full-bridge converter. So this TTPP converter has a similar operation theory as phase-shifting full-bridge converter. Its two primitive power switches can obtain wide range ZVS. The extra power switch can achieve ZVS based on the energy of the leakage inductance. Its transformer waveform is as same as that in phase-shifting full-bridge circuit. As a result, this TTPP converter has a characteristic between traditional push-pull converter and phase-shifting full-bridge converter. It could be applied in many fields.

\section{Acknowledgements}

This work is supported by National Natural Science Foundation of China (51067004), Key Science and Technology Project of Jiangxi Province of China (2010BGA02000) and Science and Research Foundation of Educational Department of Jiangxi Province in China (GJJ12293).

\section{REFERENCES}

[1] W. Chen, F. C. Lee, M. M. Jowanovic and J. A. Sabatec, "A Comparative Study of a Class of Full Bridge Zero-voltage-switched PWM Converter," in Proceedings of IEEE APEC, Dallas, USA, 1995, pp. 893-895.

[2] X. K. Wu, X. G Xie, C. Zhao, Z. M. Qian and R. X. Zhao, "Low Voltage and Current Stress ZVZCS Full Bridge DC-DC Converter Using Center Tapped Rectifier Reset," IEEE Transactions Industry Electronics, Vol. 55, 2008, pp. 1470 - 1477.

[3] I. H. Cho, K. M. Cho, J. W. Kim and G. W. Moon, “A New Phase-Shifted Full-Bridge Converter with Maximum Duty Operation for Server Power System," IEEE Transactions on Power Electronics, Vol. 26, 2011, pp. 3491-3500.

[4] Y. Jang and M. M. Jovanovic, "A New PWM ZVS Full-Bridge Converter," IEEE Transactions on Power Electronics, Vol. 22, 2007, pp. 987-994. doi:10.1109/TPEL.2007.897008

[5] X. K. Wu, X. G. Xie, J. M Zhang, R. X. Zhao and Z. M. Qian, "Soft Switched Full Bridge DC-DC Converter With Reduced Circulating Loss and Filter Requirement," IEEE Transactions on Power Electronics, Vol. 22, 2007, pp. 1949-1955. doi:10.1109/TPEL.2007.904211

[6] H. K. Yoon, S. K. Han, J. S. Park, G. W. Moon and M. J. Youn, "Zero-Voltage Switching Two-Transformer Full-Bridge PWM Converter With Lossless Diode-Clamp Rectifier for PDP Sustain Power Module, "IEEE Transactions on Power Electronics, Vol. 21, 2011, pp. 1243-1252.doi:10.1109/TPEL.2006.880346

[7] B. Yang , F. C. Lee and A. J. Zhang, et al., "LLC Resonant Converter for Front End DC/DC Conversion," in Proceedings of IEEE APEC, Dallas, USA, 2002, pp. 1108-1112.

[8] I. O. Lee and G. W. Moon, "Analysis and Design of a Three-Level LLC Series Resonant Converter for Highand Wide-Input-Voltage Applications," IEEE Transactions on Power Electronics, Vol. 27, 2012, pp. 2966-2979. doi:10.1109/TPEL.2011.2174381

[9] X. G. Xie, J. M. Zhang, C. Zhao, Z. Zhao and Z. M. Qian, "Analysis and Optimization of LLC Resonant Converter With a Novel Over-Current Protection Circuit," IEEE Transactions on Power Electronics, Vol. 22, 2007, pp. 435-443.

[10] K. Y. Yi and G. W. Moon, "Novel Two-Phase Interleaved LLC Series-Resonant Converter Using a Phase of the Resonant Capacitor," IEEE Transactions on Industrial Electronics, Vol. 56, 2009, pp. 1815-1819. doi:10.1109/TIE.2008.2011310

[11] Y. L. Gu, Z. Y. Lu, L. J. Hang, Z. M. Qian and G. S. Huang, "Three-level LLC series resonant DC/DC converter," IEEE Transactions on Power Electrionics, Vol. 20, 2005, pp. 781-789. doi:10.1109/TPEL.2005.850921

[12] M. Xu, Y. C. Ren, J. H. Zhou and F. C. Lee, "1-MHz Self-driven ZVS Full-bridge Converter for 48-V Power Pod and DC/DC Brick," IEEE Transactions on Power Electronics, Vol. 20, 2005, pp. 997-1006.

[13] I. Boonyaroonate and S. Mori. "A New ZVCS Resonant 
Push-pull DC/DC Converter Topology," in Proc.IEEE APEC Dallas, USA, 2002, pp. 1097-1100.

[14] Y. S. Yuan, J. Y. Shu and Q. F. Wu, "N-period Resonant Behaviour of a Soft-switching Push-pull Conveter," in Proceedings of IEEE-ISIE, Hangzhou, China, 2012, pp. 397-401.

[15] M. J. Ryan, W. E. Brumsickle, D. M. Divan and R. D. Lorenz, "A New ZVS LCL-resonant Push-pull DC-DC Converter Topology," IEEE Transactions on Industry Applications, 1998, pp. 1164-1174. doi:10.1109/28.720458

[16] Y. S. Yuan, M. Chen and Z. M. Qian, "A Parallel Front-End LCL Resonant Push-Pull Converter with a Coupled Inductor for Automotive Applications," in Proceedings of IEEE APEC, Palm Springs, USA, 2010, pp. 1460-1463
[17] H. Ma, H. X. Yu and Y. Y. Yan, "Investigation on LCL Resonant Converter as Current Source," in Proceedings of CSEE, Vol. 29, No. 9, 2009, pp. 28-34

[18] W. Chen, Z. Y. Lu, X. F. Zhang, et al., " A Novel ZVS Step-up Push-pull Type Isolated LLC Series Resonant DC-DC Converter for UPS Systems and Its Topology Variations," in Proceedings of IEEE APEC, Austin, USA, 2008, pp. 1073-1078.

[19] T. F. Wu, J. C. Hung, J. Z. Tsai and Y. M. Chen, "An Active-clamp Push-pull Converter for Battery Sourcing Application," IEEE transactions on Industry Applications, Vol.44, 2008, pp.196-204.

[20] Y. D. Ma, L. Q. Zhou, X. B. Ruan and Y. G. Yan, “Zero-voltage-switching PWM Push-pull Three-level Converter," in Proceedings of CSEE, Vol. 26, No. 23, 2006, pp. 36-41. 